\title{
Application of Treatment Simulation Software for War Injury in Emergency Treatment Training on the Battlefield based on Chinese Visible Human Datasets
}

\section{Xin $\mathrm{Hu}$}

Third Military Medical University: Army Medical University

Li Liu

Third Military Medical University: Army Medical University

\section{Zhou Xu}

Third Military Medical University: Army Medical University JingYi Yang

Third Military Medical University: Army Medical University

\section{HongFeng Guo}

Department of combat casualty care training , Army Training Base for Health Care, Army Medical University

\section{Ling Zhu}

Army Military Medical University: Army Medical University

Yi Wu ( $\square$ wuy1979@tmmu.edu.cn )

Army Military Medical University: Army Medical University

\section{Research}

Keywords: Chinese Visible Human, Military medicine, War trauma treatment, Sectional anatomy

Posted Date: January 21st, 2021

DOI: https://doi.org/10.21203/rs.3.rs-150806/v1

License: (c) (i) This work is licensed under a Creative Commons Attribution 4.0 International License. Read Full License 


\section{Abstract}

Background: Proficiency in self-help and mutual aid skills is correlated with the prognosis of injured patients, and this study aims to create treatment simulation software for war injuries that reflect the physical constitution of Chinese people and study its application in first aid training on the battlefield.

Methods: Based on thin-sectional, highly precise Chinese Visible Human (CVH) data with high resolution, combined with self-help and mutual medical aid measures such as digital pressure hemostasis, cricothyroid membrane puncture, pneumothorax puncture and bone marrow puncture for battlefield first aid, useing Amira and other softwares to building the simulation software for the technical training of military medical students and basic medical officers was constructed. Eighty medical service students were trained on battlefield first aid technology, and a new training mode for the treatment of war injuries was developed and optimized.

Results: Simulation software of hemostasis and puncture for battlefield first aid that was suitable for the technical training of military medical students and its supporting teaching materials 3D-PDF were established. The software included modules of hemostasis of the vertex, face, head-shoulder, shoulderarm, forearm, upper forearm, lower limb and foot and puncture of the cricothyroid membrane, pneumothorax, and bone marrow cavity. Collaborating with interactive 3D-PDF, it was successfully used for on-site first aid training of military medical students. The questionnaire results showed that the trainees had a high recognition of the human-computer interactive performance of the software with a clear interface and easy operation. The accuracy and richness of the three-dimensional model structure, knowledge of hemostasis and puncture and applied anatomy contained in this software were high, helping trainees to quickly master the knowledge points and operation techniques related to hemostasis and puncture.

Conclusion: The system can effectively mobilize the learning enthusiasm of students and fully improve the learning efficiency of the basic materials and applied anatomy of battlefield first aid, as well as the teaching efficiency of teachers. The training simulation of battlefield first aid, comprising a combination of various modes, effectively complemented each other, met many training needs, and achieved satisfactory training results. Additionally, this software could be used in the emergency training of traffic accident injuries and disaster-related injuries.

\section{Full Text}

Due to technical limitations, full-text HTML conversion of this manuscript could not be completed. However, the latest manuscript can be downloaded and accessed as a PDF.

\section{Figures}




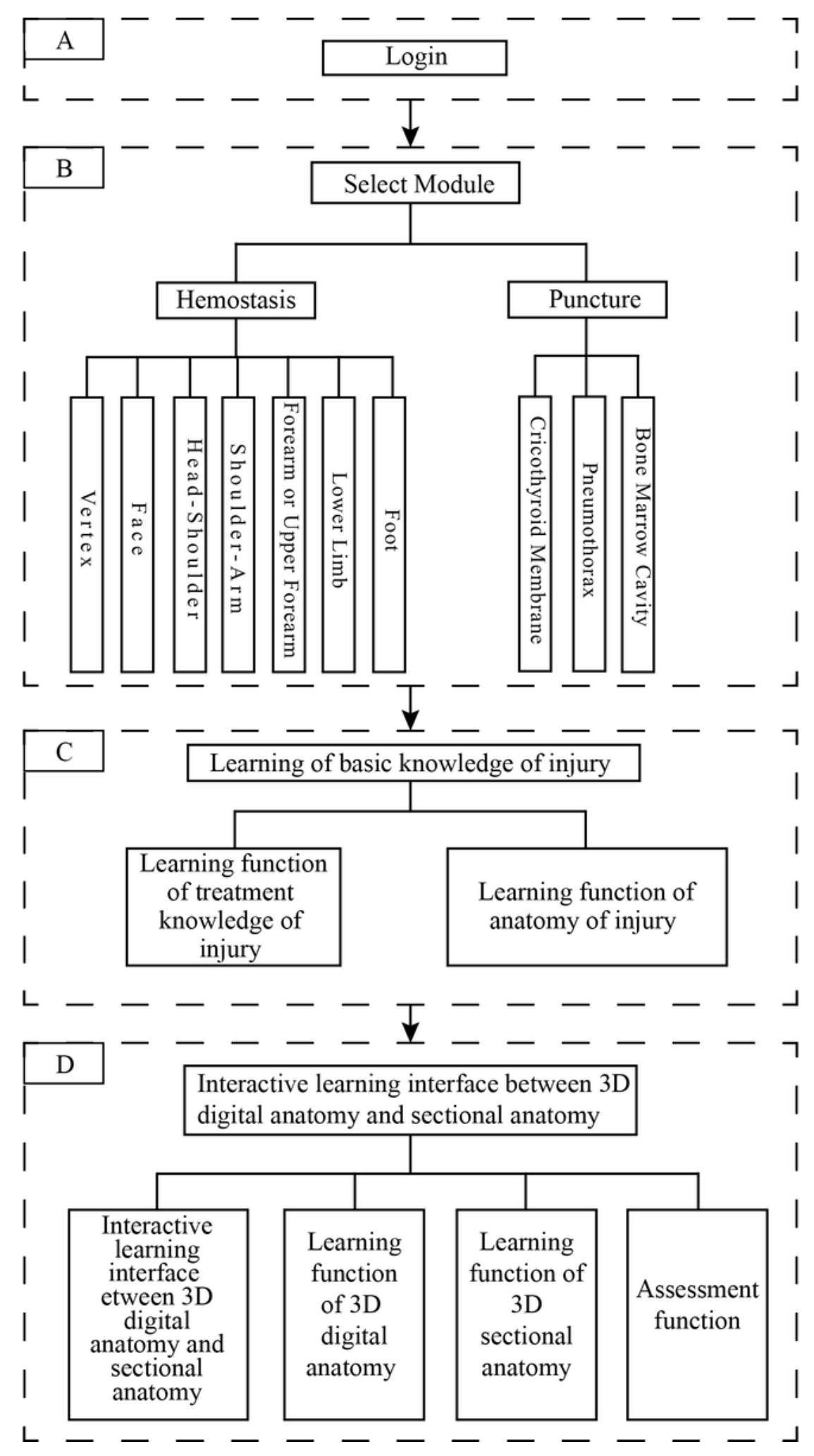

Figure 1

Flow chart of software construction 


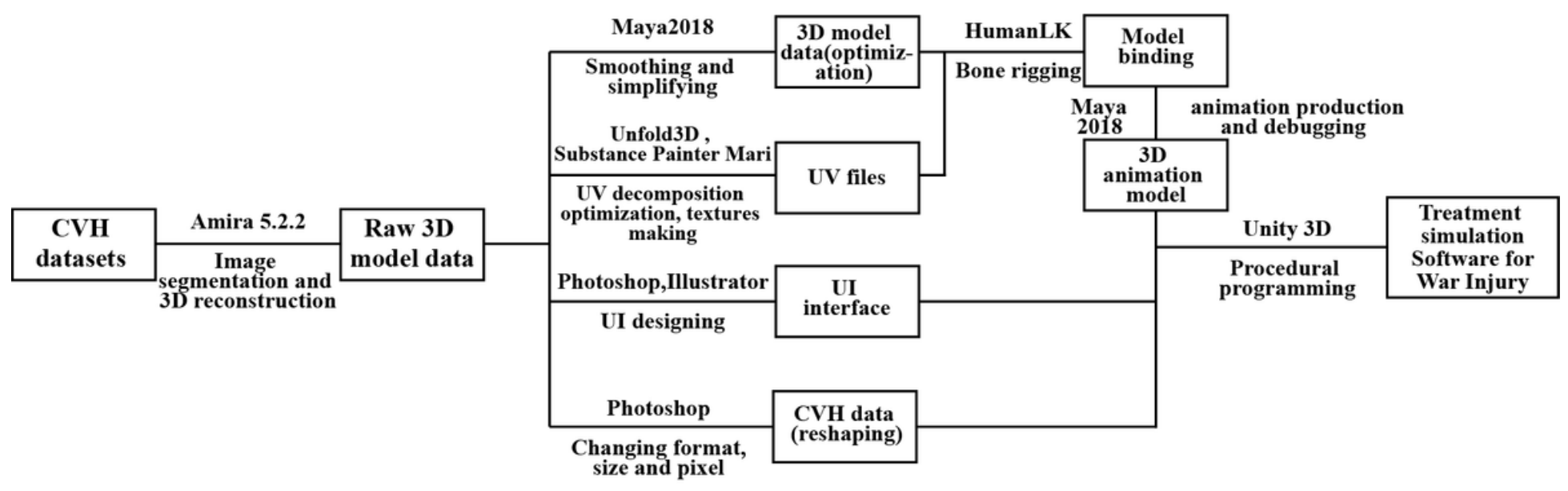

\section{Figure 2}

Frame diagram of treatment simulation software by hemostasis and puncture on the battlefield. A: Firstlevel interface; B: Second-level interface; C: Third-level interface; D: Fourth-level interface. 


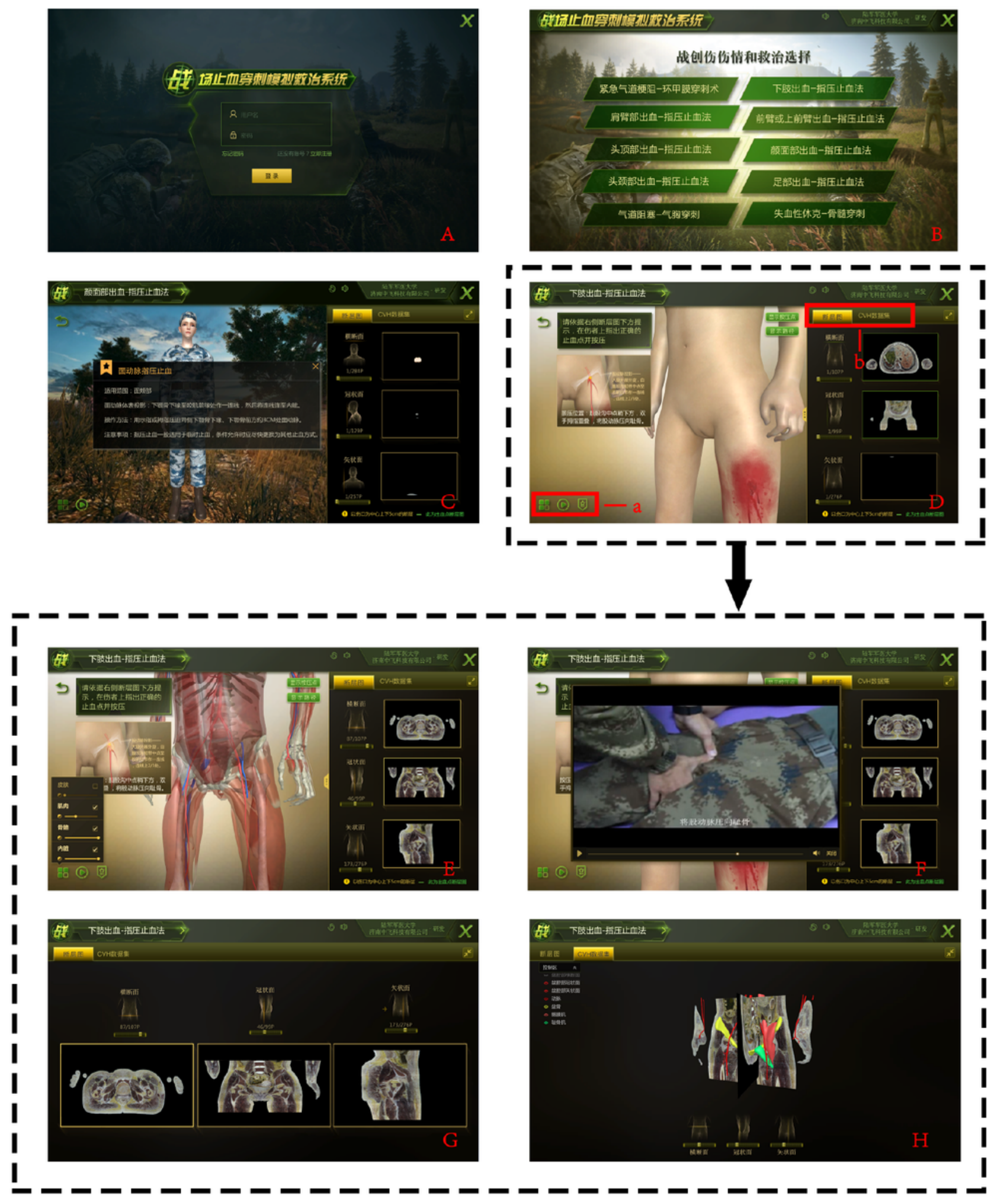

Figure 3

Interface of the software. A. Interface of the user login. B. Interface of the module selection, providing the function of injury module selection. C. Module of learning basic knowledge of the injury. D. Interactive learning interface of the 3D digital anatomy and sectional anatomy. E. Interaction with the 3D model. F. Video teaching. G. Learning function of the sectional images. $\mathrm{H}$. Learning function of $\mathrm{CVH}$ and the 3D 
model. a. Click area of the 3D model structure control, video teaching and tips. b. Sectional image learning, CVH and 3D model learning button area.
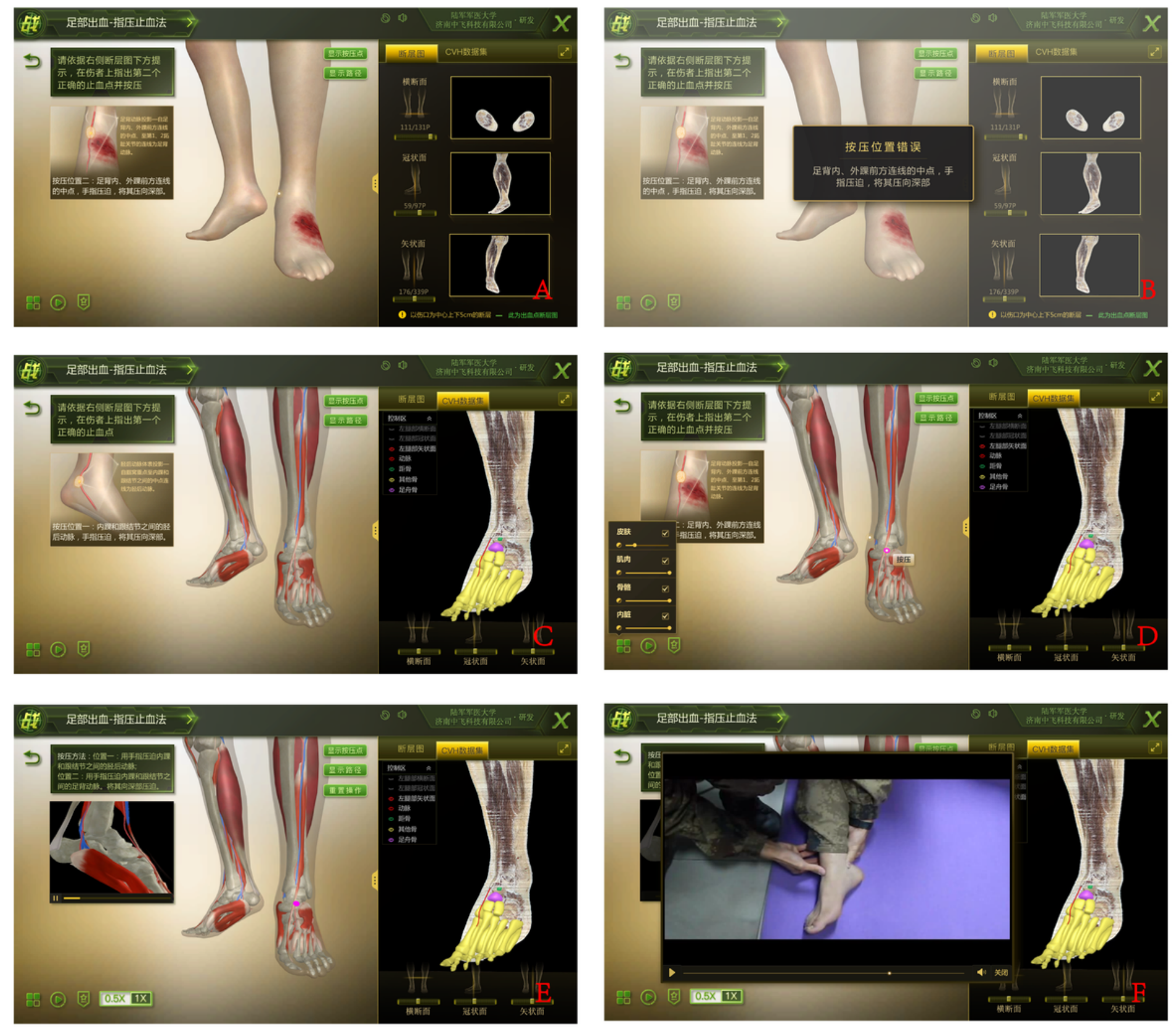

\section{Figure 4}

Functional demonstration of the hemostasis of the foot by pressing. A. Observation of the injury. B. Pressing of the wrong position and observation of error clues. C. Transparency of the skin, observation of the injury deeply to identify the correct hemostatic pressing point. D. Selection of the correct pressing position. E. Animated demonstration of pressing and helping trainees observe the situation of vascular compression and adjacent relationship between the pressing position and injury. F. Teaching video of hemostatic pressing demonstrating the operation techniques. 

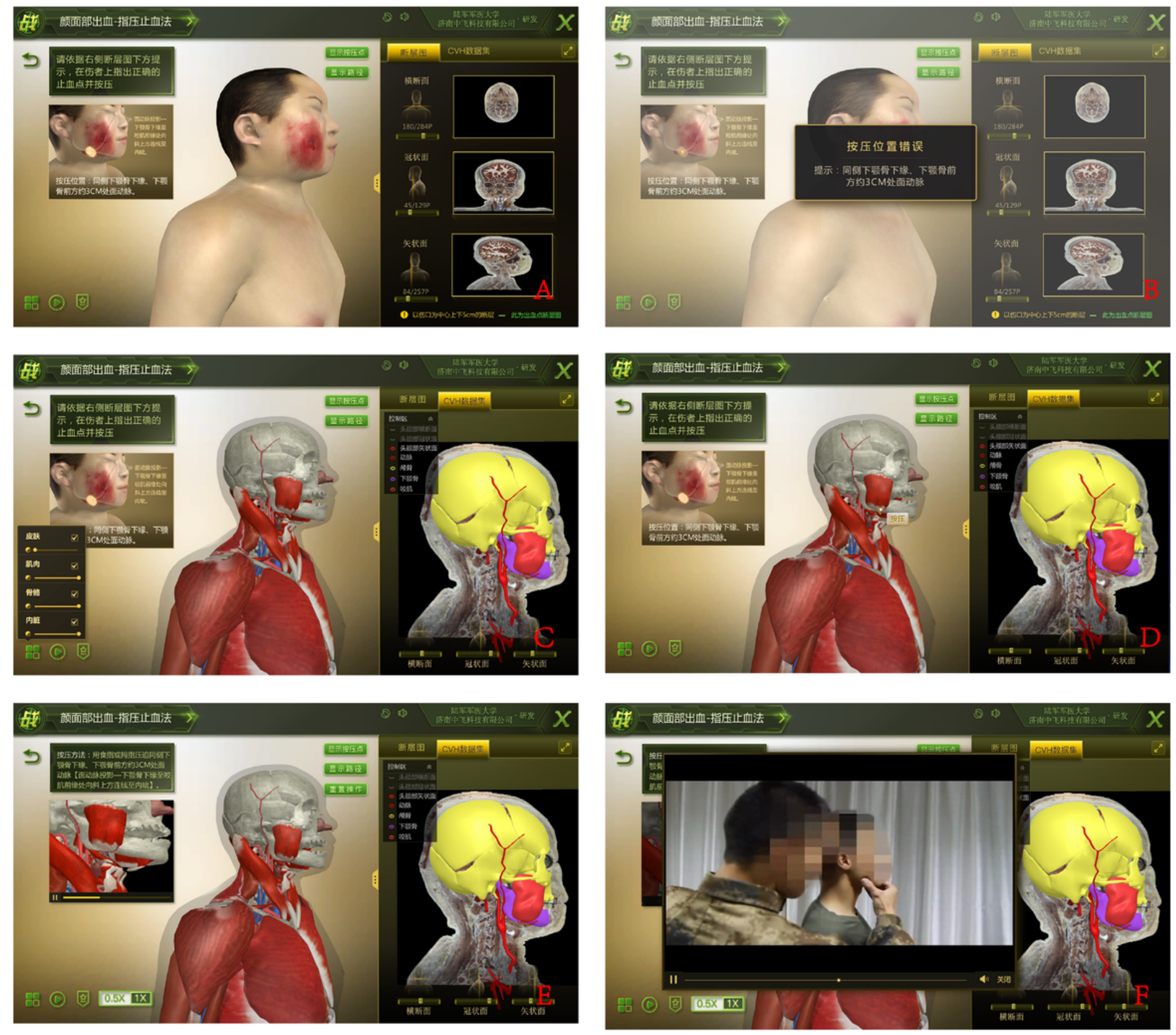

\section{Figure 5}

Pressing to stop bleeding on the face. A. Observation of the injury. B. Pressing of the wrong position and observation of error clues.; C. Transparency of the observation of the injury deeply to identify the correct hemostatic pressing point. D. Selection of the correct pressing position. E. Animated demonstration of pressing and helping trainees observe the situation of vascular compression and adjacent relationship between the pressing position and injury. F. Teaching video of hemostatic pressing, demonstrating the operation techniques. 

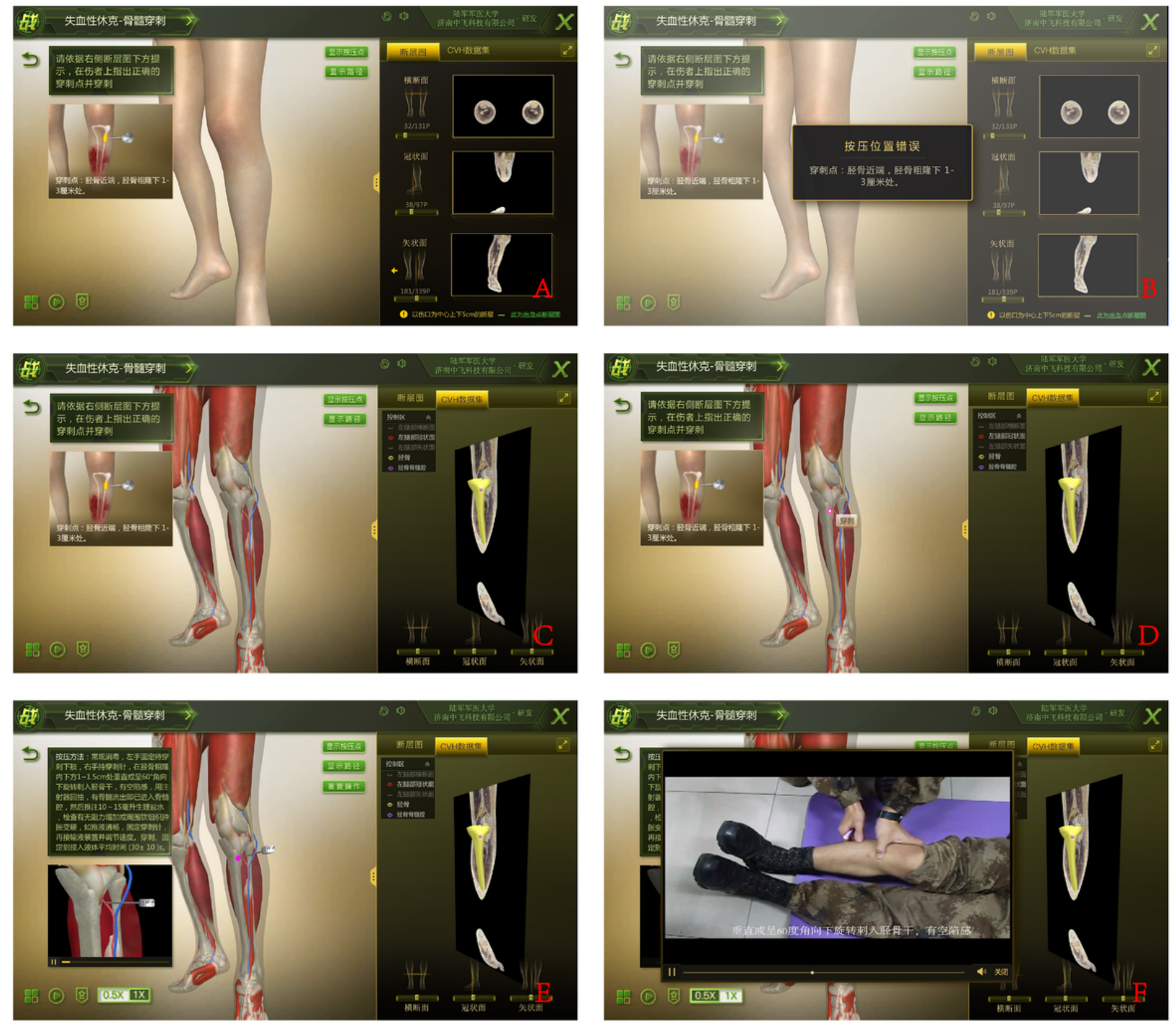

\section{Figure 6}

Bone marrow puncture. A. Observation of the injury; B. Selection of the wrong puncture position and observation of error clues. C. Transparency of the skin and observation of the injury deeply to identify the correct puncture point. D. Selection of the correct puncture position and confirmation to proceed to the next step. E. Animated puncture demonstration to help trainees observe the angle, approach and depth of the puncture. F. Teaching video confirming the puncture point. 


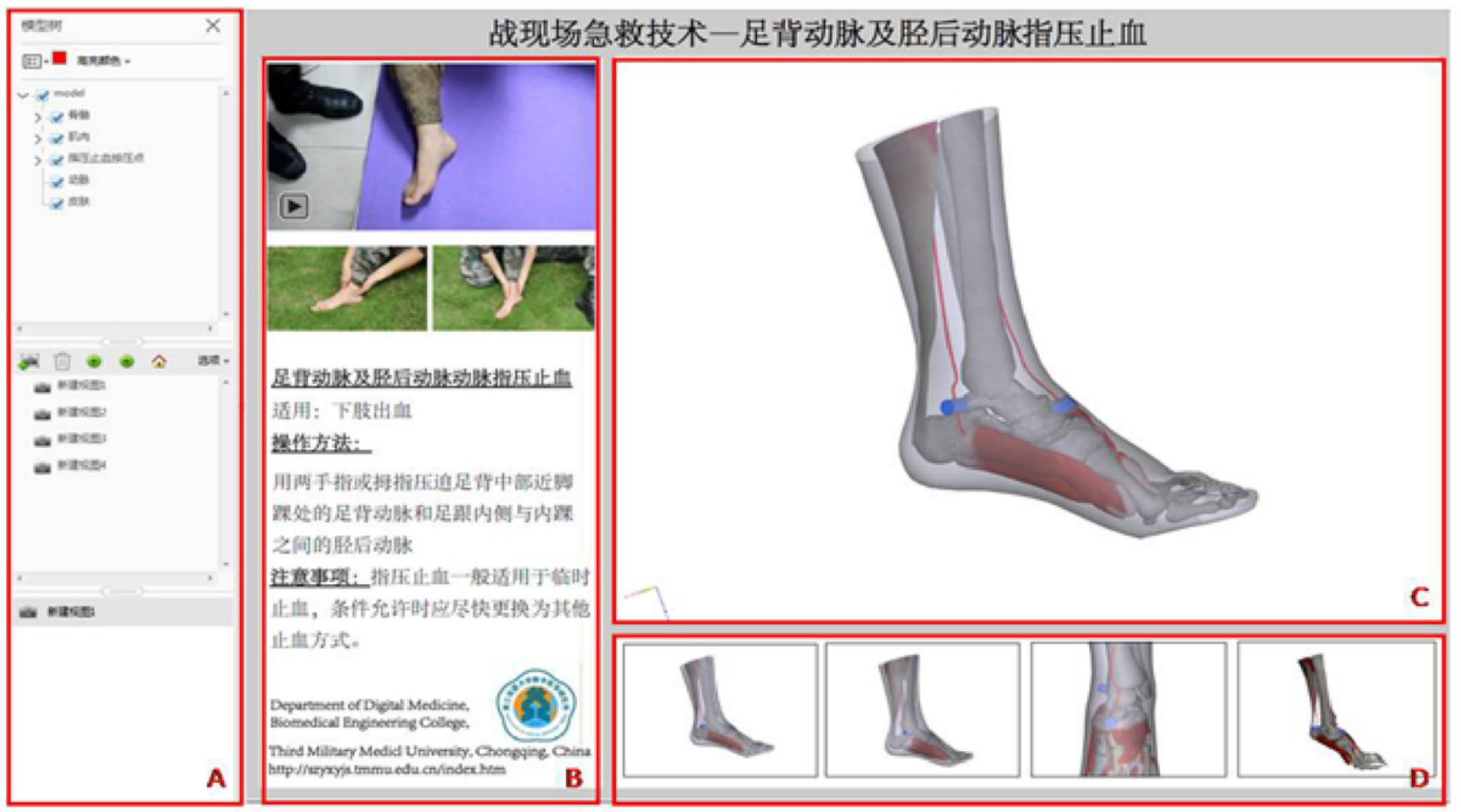

\section{Figure 7}

3D-PDF interface of digital pressure hemostasis of the dorsal pedal artery and posterior tibial artery. A. Functional area of the model tree. B. Functional area of the video and image and text. C. 3D view area; D. Preset view area. 